\title{
Public Regulation of Agricultural Biotechnology Field Tests: Economic Implications of Alternative Approaches
}

\author{
Bruce A. Larson and Mary K. Knudson
}

\begin{abstract}
Federal oversight of agricultural biotechnology field testing is based on public concerns that unknown consequences could arise from such tests, and that firms may not adequately consider the public consequences of their research and development activities. In this paper, four general types of ex ante and ex post approaches to manage public risks from field testing are explored. The analysis shows that the approaches are least effective at facilitating the research process yet controlling public risks when the research firm is small in size and potential damages exceed the value of the firm.
\end{abstract}

Key words: biotechnology, environmental bond, field tests, liability, standards.

The Food Security Act of 1985 authorized the secretary of agriculture to establish "appropriate" controls over the development and use of biotechnology in agriculture. Since that time, the U.S. Department of Agriculture (USDA) in conjunction with other federal agencies, university officials, and private industry have attempted to define "appropriate" controls and procedures for their implementation. The need for such controls was based on public concerns that unknown consequences or hazards could arise from such tests and that private firms may not adequately consider the public consequences of their research and development activitics. For example, genetically altered microbes could escape from containment facilities of a field test and cause unexpected harm to nearby fields. Modified crops with new specific traits, such as herbicide resistance, drought resistance, or pest resistance, could develp weedy cousins that take over local ecosystems and increase control costs.

Based on the National Institute of Health's

Bruce A. Larson is an economist in the Resources and Technology Division, Economic Research Service. U.S. Department of Agriculture. Mary $\mathbf{K}$. Knudson is an economist with the Institute of Public Policy Studies, University of Michigan.

The views expressed in this paper are the authors' and do not necessarily reflect the views or policies of the Economic Research Service.

The authors wish to thank, without implicating, Kathleen Segerson, Richard Ready, and an anonymous Journal referee for helpful comments and suggestions.
"Guidelines for Research Involving Recombinant DNA Molecules" (NIH), the Office of Science Technology and Policy published the "Coordinated Framework for Regulation of Biotechnology" (OSTP). The "Coordinated Framework," which outlines the federal plan for regulating uses of biotechnology, was intended to provide guidance to researchers for the safe development of biotechnology. The "Coordinated Framework" generally identified permits that may be needed from various agencies to conduct biotechnology experiments. The main agencies responsible for agricultural technologies are the USDA's Animal and Plant Health Inspection Service (APHIS), through various regulations for plant pests and animal biologics, and the Environmental Protection Agency, through the Federal Insecticide, Fungicide, and Rodenticide Act (FIFRA) and the Toxic Substances Control Act (TSCA). However, the "Coordinated Framework" focused on laboratory testing while virtually ignoring field testing (OAB March 1990).

The USDA Office of Agricultural Biotechnology (OAB) has also proposed the voluntary "Guidelines for Research Outside the Laboratory Involving Biotechnology," which apply to institutions receiving any USDA support for research with genetically modified organisms (OAB 21 May 1990). While OAB recommendations under the guidelines are not binding on an in- 
stitution or a private company, ignoring the OAB's recommendations might increase the company's liability if something were to go wrong with the experiment. Conversely, if an institution or company follows $\mathrm{OAB}$ recommendations, "those extra steps could be seen as 'reasonably prudent' should an unforeseen negative consequence result from the actual field trial" (OAB March 1990, p. 6).

Despite federal efforts, however, a unified approach for regulating field testing that involves biotechnology has not been developed. It also remains unclear how companies will gain approval to market some products produced using modern methods of biotechnology. As a result, some companies have decided to avoid using such methods in product development (Crawford). A consistent and coordinated regulatory environment is necessary to reduce costs and uncertainty associated with the regulatory environment while assuring adequate protection for the environment and human health (GAO, NRC).

The primary purpose of this paper is to explore how different policies alter the choice problem of the firm and influence the allocation of funds to existing and new research and development activities. In theory, and ignoring transaction costs, a Coasian-type bargaining arrangement between biotechnology researchers and local groups could be developed to determine a technology regulation policy (Coase). Of course, such bargaining can take place only after an initial assignment of property rights (Demsetz). Thus, the analysis in this paper, which analyzes the implications of the initial assignment of rights, is logically prior to such bargaining; and the type of policies for regulating biotechnological research and development will influence any later bargaining attempts. In practice, biotechnology companies are concerned that each state will establish separate policies (Crawford). A federal policy on biotechnology field testing coordinated with state agencies would probably reduce costs in the regulatory oversight process, both to firms and regulatory agencies, and provide consistent signals for research across locations. ${ }^{1}$

The approach in this paper follows the literature on ex ante regulation and ex post liability (Johnson and Ulen; Rizzo; Segerson; Shavell

\footnotetext{
${ }^{\prime}$ For example. since Monterey County. California, passed an ordinance requiring a full environmental review and permit for field testing in 1986. no applications have been filed, and ficld testing occurs elsewhere.
}

1987, 1984a, b, 1980; White and Wittman). Focusing specifically on the case of unilateral accidents, where only the firm's behavior affects risks, we analyze how four different approaches-a fixed-cost regulatory standard, a marginal-cost standard, a property rule, and a strict-liability rule-influence the allocation of funds to research and safety activities.

\section{Background and Model Assumptions}

Much of environmental economics and the integration of law and economics is devoted to studying the appropriate means of regulating potentially hazardous activities. Following Weitzman, the "prices versus quantity" literature analyzed two general types of ex ante policies for controlling stochastic externalities: a marginal pollution tax on firm choices equal to the expected marginal social damage or a constraint on firm pollution equal to the expected social optimum (Fishelson; Watson and Ridker; White and Wittman; Yohe 1976, 1978). In the end, either approach could be preferred, depending on the shape of the expected benefit and cost functions.

Recognizing the stochastic and sequential nature of many externalities, another group of articles has analyzed the use of $e x$ ante regulation and $e x$ post liability to induce firms to internalize environmental risks (Johnson and Ulen; Rizzo; Segerson; Shavell 1987, 1984a,b, 1980; White and Wittman). For example, under a regulatory standard, a firm must comply with the standard - spend a certain amount on "safety" - before conducting an activity. Under strict liability for damages, the firm fully compensates injured parties if an accident occurs and if it can be shown that the firm's actions caused the damages. A negligence rule is another approach, where the firm may not be held responsible for any damages if it follows stipulated standards or guidelines (Kahan). Characteristic of the literature on liability is that either safety decisions of the firm are assumed to be separable from its main economic activities (Johnson and Ulen, Segerson, Shavell 1984a, Tietenberg) or the firm is assumed to earn risk-free returns from a single activity (Shavell 1987, 1980).

In contrast to existing studies, we explicitly consider the economic incentives of a firm with the opportunity to engage in a new research activity, such as field testing of crops produced using modern biotechnology methods. Thus, we analyze the case where $(a)$ safety decisions are 
not separable from the main activities of the firm, (b) the firm engages in a riskless existing activity and a risky new activity, and (c) the firm has a fixed amount of initial wealth or research budget at its disposal. While a simplification, the case analyzed here captures the decision problem facing research and development (R\&D) firms in the biotechnology industry. In general, R\&D firms engage in multiple projects. While some R\&D projects, such as further development of existing products, may offer relatively certain returns and pose little risk, more basic research may be much more uncertain. ${ }^{2}$ On the other hand, the risks of harm associated with applied field testing of new crop varieties developed with modern biotechnology methods are considered more risky than varieties created through traditional breeding methods.

The allocation of firm wealth among existing and new research activities is a portfolio allocation problem. For example, consider a research and development firm with initial assets (or research budget) of $x>0$ that has the opportunity to conduct a riskless and risky activity. The riskless activity earns a constant marginal rate of return of $r$ on each dollar with no possibility of external damages. Field testing of traditional varieties or a riskless financial asset are examples of riskless activities. The risky activity, which involves field testing of a new product developed with biotechnology methods, earns a reward equal to $B$ with a probability of success $p(\bullet)$, where $p(\bullet)$ is an increasing and concave function of firm assets allocated to the risky activity. ${ }^{3}$ The risky activity can also cause damage outside the firm equal to $h$ with probability $d(\bullet)$, where $d(\bullet)$ is an increasing and convex function of firm assets allocated to Activity $2 .{ }^{4}$ Modeling uncertainty in the research process and the externality process as independent Bernoulli distributions with parameters $p(\bullet)$ and $d(\bullet)$ provides enough generality while retaining clear implications of the model. Such assumptions are common (Shavell 1984a, Tietenberg).

\footnotetext{
${ }^{2}$ Randomness in benefits and externalities is common to many industries, not just biotechnology R\&D because of biological or geological uncertainties (e.g., the spatial distribution of mineral reserves and animal populations) and weather

3 While we will use the term "risky" activity, the probability distributions may not be known with certainty, and, therefore, the mode could involve decision making under uncertainty or risk.

${ }^{4}$ Because $h$ is constant and $d(\bullet)$ depends only on firm actions, only the incentives for safety or precaution of the firm are considered. Thus, injured parties cannot take precautionary actions to reduce the level of harm.
}

The structure of the model develped here is a straight forward generalization of existing models that focus on minimizing the cost of safety precautions for the risk-neutral firm (Shavell 1984a, Johnson and Ulen, and Tietenberg). However, the model is specifically designed to illustrate how a firm with the opportunity to conduct a particular research project responds to different regulatory approaches. Of course, because the cost of various $R \& D$ programs vary widely, different size firms will generally select from a different set of projects.

While the probability functions $p(\bullet)$ and $d(\bullet)$ depend only on the amount of money allocated to the risky activity, the probability functions could be written more generally as $p\left(\mu_{1} x\right)$ and $d\left(\mu_{1} x, \mu_{2} x\right)$, where $\mu_{1}$ is the percentage of assets allocated to the risky activity, $\mu_{2}$ is the percentage of assets allocated to safety activities, and $1-\mu_{1}-\mu_{2}$ is allocated to the riskless activity. The function $d(\bullet)$ would be increasing in $\mu_{1}$ and decreasing in $\mu_{2}$, with $d(\bullet)$ convex. For some problems, safety activities may impede the productivity of the resources allocated to the risky activity, or a reduction in potential damage can be obtained only by using a different and less productive technology. In such cases, the probability of success could also be written as $p\left(\mu_{1}, \mu_{2}\right)$, where $p(\bullet)$ is increasing in $\mu_{1}$, nonincreasing in $\mu_{2}$, and concave. To clarify the analysis without changing its basic qualitative nature, it is assumed that resources allocated to safety activities substitute for resources allocated to the risky activity in the probability of damage function $d(\bullet)$. Thus, the firm implicitly chooses $\mu_{2}=0$ and controls the probability of damage through the allocation of resources to the risky activity. For example, easy substitution in the probability of damage function occurs in biotechnology field testing: the size of the experiment can be reduced, but containment facilities and other safety activities can also be reduced, leaving the probability of damage relatively constant.

In the absence of regulations, a firm has no incentive to internalize the possibility of damage from its actions into the decision-making process. Assuming the firm allocates wealth between the riskless and risky activities to maximize expected profits, the firm's problem becomes

$$
\max _{0 \leq \mu \leq 1}(1+r)(1-\mu) x+p(\mu x) B
$$

where the first term in (1) is income from the 
riskless activity and the second term is the expected return from the risky activity.

Assuming an interior solution, the first-order condition for expected profit maximization can be rearranged to yield

$$
(1+r)=p^{\prime}\left(\mu^{f} x\right) B
$$

where $\mu^{f} \equiv \mu^{f}(1+r, x, B)$ is the firm's optimal percentage of assets allocated to the risky activity, which is decreasing in $1+r$ and $x$ and increasing in $B$. Concavity of $p(\bullet)$ ensures second-order conditions for a maximum are satisfied at an interior solution. Equation (2) has the usual interpretation that the firm equates the marginal rate of return for the riskless activity to the marginal expected benefits for the risky activity. A corner solution $\mu^{f}=0\left(\mu^{f}=1\right)$ exists when the rate of return on the riskless activity is everywhere greater (less) than the expected marginal benefits from the risky activity.

It is also illustrative to consider the case where society maximizes the sum of expected net benefits from riskless and risky activities. ${ }^{5}$ Society's problem is

$$
\begin{aligned}
\underset{0 \leq \mu \leq 1}{\operatorname{maximize}}(1+r)(1-\mu) x & \\
& +p(\mu x) B-d(\mu x) h,
\end{aligned}
$$

where the terms in (3) are returns from riskless and risky activities and expected harm from the risky activity.

At an interior solution, the first-order condition for problem (3) can be rearranged to yield

$$
(1+r)=p^{\prime}\left(\mu^{s} x\right) B-d^{\prime}\left(\mu^{s} x\right) h,
$$

where $\mu^{s} \equiv \mu^{s}(1+r, x, B, h)$ is society's optimal investment choice, which is decreasing in $1+r, x$, and $h$ but increasing in $B$. Concavity of $p(\bullet)$ and convexity of $d(\bullet)$ ensure that second-order conditions are satisfied at an interior solution. Equation (4) has the usual interpretation that society equates the return from the riskless activity to the expected marginal net social benefits from the risky activity. A corner solution of $\mu^{s}=0$ may occur as potential harm grows relative to benefits.

Problem (3) identifies the quandary facing society and policy makers. Society values the ben-

\footnotetext{
'Because benefits and costs do not fall on identical parties, in which case the utility effects are not comparable, we do not imply that expected net benefits should be society's welfare criteria. However, the net-beneftit objective remains a basis for comparing altemative regulatory approaches found in earlier works
}

efits from both riskless and risky activities but wants to limit its exposure to harm. Thus, the regulatory question involves designing institutions that provide the incentives for the firm to internalize expected damages $d(\mu x) h$ from the risky $R \& D$ activity.

\section{Approaches for Controlling Public Risk}

In the absence of a regulatory authority that can force a firm to allocate funds according to some social optimum, indirect methods must be used to provide the incentives for the firm to internalize potential externalities. Four approaches are considered: a fixed-cost regulatory standard, a marginal-cost regulatory standard, a property rule, and a strict-liability rule. While not explicitly considered in this paper, the model could also be generalized to analyze a negligence rule or the joint use of ex ante and ex post institutional approaches, such as a standard combined with a strict-liability rule. ${ }^{6}$

\section{A Fixed-Cost Regulatory Standard}

Consider first a fixed-cost regulatory standard, where $q$ represents the cost of following the standard for conducting the risky activity. Given that the cost of the standard directly reduces a firm's assets, the expected-profit maximization problem of the firm becomes

$$
\begin{aligned}
\underset{0 \leq \mu \leq 1}{\operatorname{maximize}}(1+r)(1-\mu)( & (x-q) \\
& +p(\mu(x-q)) B,
\end{aligned}
$$

where the first term is income from the riskless activity, the second term is expected returns from the risky activity, and $\mu$ is the percentage of assets $(x-q)$ allocated to the risky activity. Although $q$ is a fixed cost of conducting the risky activity, the level of $q$ reduces firm wealth, which in turn affects the firm's choice of $\mu$. The firm will allocate funds to the risky investment according to the optimum in equation (5) as long

\footnotetext{
' Under a negligence rule, three basic conditions must be met for a firm to be held responsible for damages (Kahan). It must be shown that $(a)$ the firm did not follow a stipulated level of due care, $(b)$ damages were actually suffered, and $(c)$ the firm's lack of due care actually causcd the damages. In some situations, any contribution to damages created by the complaining party may also be considered. See Shavell (1987) and Kahan for more complete discussions.
} 
as the resulting expected profit is greater than $(1+r) x$. Thus, a standard could drive the firm out of the risky activity altogether, even though some level of the activity is socially desirable.

At an interior optimum, the first-order condition to (5) can be rearranged to yield

$$
(1+r)=p^{\prime}\left(\mu^{n}(x-q)\right) B,
$$

where $\mu^{n} \equiv \mu^{f}(1+r, x-q, B)$ is the firm's optimal investment decision under the standard, which is decreasing in $r$ and $x$ and increasing in $B$ and $q$.

When $0<\mu^{n}<1$, equations (2) and (6) imply that $1+r=p^{\prime}\left(\mu^{n}(x-q)\right) B=p^{\prime}\left(\mu^{f} x\right) B$, which occurs when $\mu^{f} x=\mu^{n}(x-q)$. Thus, the total level of investment in the risky activity under a standard remains equal to the level of investment for the unregulated firm. To maintain this equality of the marginal rates of return across the two activities, the firm under a regulatory standard must increase the percentage of its remaining assets to the risky activity.

Because the level of investment in the risky activity remains the same with or without the standard at an interior solution, society also faces the same amount of risk, i.e., $d\left(\mu^{f} x\right)=d\left(\mu^{n}(x\right.$ $-q)$ ). This result, while extreme in quantitative magnitude, is qualitatively similar to a result in Segerson and focuses on an important feature of a regulatory standard. The firm's ability to substitute around a standard to equalize rates of return across activities determines the effectiveness of a fixed-cost standard in reducing public risk. In Segerson, where standards are placed on only observable actions of the firm, a regulatory standard provides the incentive to substitute into unobservable actions. Thus, the degree of substitution in the probability function $d(\bullet)$ between directly productive activities and safety activities determines how effective the standard is in reducing risk.

\section{A Marginal-Cost Regulatory Standard}

The second approach is a constant marginal-cost standard, where a firm pays a fixed amount $\tau$ per unit of investment in the risky activity. Thus, if $\mu x$ is invested in the risky activity, the firms pays $\tau \mu x$ in tax, and invests $(1-\mu-\tau \mu) x$ in the riskless activity. Thus, the cost of following the standard increases with the investment in the risky activity.

For example, the USDA guidelines identify four levels of confinement, such as physical barriers to limit the release of an organism to the environment, that correspond to five levels of safety concerns identified in the document (OAB 21 May 1990). The NIH guidelines refer to four levels of containment, with level four being the most restrictive and costly (NIH). While both guidelines refer to the "safety" of the experiment, one way to improve safety is to reduce the size of the field test, either by "decreasing the number of organisms used in the experiment or decreasing the land area" $(\mathrm{OAB}$ March 1990, p. 32).

Under a marginal-cost standard, the firm's problem becomes

$$
\begin{gathered}
\max _{\mu}(1+r)(1-\mu-\tau \mu) x+p(\mu x) B \\
\text { subject to } 1 /(1+\tau) \geq \mu \geq 0,
\end{gathered}
$$

where the constraint ensures the firm does not violate its budget constraint.

Assuming an interior solution, the first-order condition can be rearranged to yield

$$
(1+r)=p^{\prime}\left(\mu^{\tau} x\right) B-\tau(1+r),
$$

where $\mu^{\tau}=\mu^{\tau}(1+r, x, B, \tau)$ is decreasing in $1+r, x$, and $\tau$ and increasing in $B$. The firm allocates funds to the risky investment according to equation (8) as long as expected profit at the optimum in (7) is greater than $(1+r) x$.

Because of the wealth constraint of the firm, a marginal-cost standard implies an equal reduction in wealth $(\tau)$ as well as the opportunity cost of the lost investment from that wealth $(\tau r)$. Thus, the total marginal cost of the standard is equal to $\tau(1+r)$. It is directly observable from equation (8) that investment under a marginalcost standard is always less than that for the unregulated firm or for the fixed-cost standard. ${ }^{7}$

\section{A Property Rule (Environmental Bond)}

With a property rule, the firm must post a bond, $S$, to conduct the risky activity, which is returned with interest if no accident occurs. ${ }^{8} \mathrm{Be}-$

\footnotetext{
The marginal-cost standard can also be interpreted as a marginal-tax rule. Note, however, from equations (4) and (8), that the optimal tax when the firm has a wealth constraint is $\tau^{*}=d^{\prime}\left(\mu^{5} x\right) h /$ $(1+r)$. Thus, at society's optimum and in the presence of constrained firm wealth, the optimal tax is less than expected marginal social damage.

${ }^{8}$ We use the term "property rule" following Bromley, and Calabresi and Melamed. In other words, under the property rule, a firm cannot interfere with society's entitlement to limit the risky activity unless the firm pays prior compensation (insurance in this case) in the form of the bond.
} 
cause the firm retains ownership of the bond $S$ when no damages are created, the property rule partially eliminates the incentives under a fixedcost standard to increase the amount of available wealth allocated to the risky activity.

Under the property rule, the firm's problem becomes $^{9}$

$$
\begin{aligned}
& \max _{0 \leq \mu \leq 1}(1+r)(1-\mu)(x-S) \\
+ & p(\mu(x-S)) B+[1-d(\mu(x-S))](1+r) S,
\end{aligned}
$$

where the first two terms in (9) are the returns from the riskless investment and the expected returns from the risky activity, the last term is the amount the firm expects to have returned after conducting the risky activity, and $\mu$ is interpreted as the percentage of assets $x-S$ allocated to the risky activity. From the firm's point of view, the bond is equivalent to allocating a predetermined amount in a third asset with an uncertain rate of return $(1+r)(1-d(\mu(x-S)))$ $<(1+r)$.

Assuming an interior solution, the first-order condition for the firm under a property rule can be rearranged to yield

$$
\begin{aligned}
(1+r)=p^{\prime}\left(\mu^{p}(x-S)\right) B \\
\quad-S(1+r) d^{\prime}\left(\mu^{p}(x-S)\right),
\end{aligned}
$$

where $\mu^{p} \equiv \mu^{p}(1+r, x-S, B,(1+r) S)$ is decreasing in $1+r$ and $x$, increasing in $B$, and indeterminate in $S$. The firm will conduct the risky activity according to equation (10) as long as profits at the optimum in equation (9) are greater than $(1+r) x$.

The allocation of funds under a property rule can be readily compared to firm choices under a regulatory standard and society's problem. First, assuming interior solutions and $d^{\prime}(\bullet)>0$, equations (6) and (10) imply that $p^{\prime}\left(\mu^{p}(x-S)\right)-$ $p^{\prime}\left(\mu^{n}(x-q)\right)=(S / B)(1+r) d^{\prime}\left(\mu^{p}(x-S)\right)>$ 0 . As a result, because of $p^{\prime}(\bullet)>0$ and the concavity of $p(\bullet), \mu^{p}(x-S)<\mu^{n}(x-q)$. Thus, with interior solutions, total investment in the risky activity under a property rule with bond $S$ is less than total investment under a standard with $\operatorname{costs} q$, and expected damages are less under the property rule than the regulatory standard.

\footnotetext{
${ }^{9}$ Another type of property rule could specify a bond $S$ that must be posted before conducting the risky activity, but the firm is reimbursed $S(1+r)-h$ if an accident occurs when $S(1+r)>h$, and the firm is liable for the additional amount $h-S(1+r)$ if an accident occurs when $h>S(1+r)$. For brevity, only one type of property rule is examined here. A variable bond nule of $S(\mu x)$ could also be considered where $S^{\prime}(\mu x)>0$.
}

Second, assuming interior solutions and a bond of $S=h /(1+r)$, equations (4) and (10) imply that $p^{\prime}\left(\mu^{s} x\right) B-d^{\prime}\left(\mu^{s} x\right) h=1+r=p^{\prime}\left(\mu^{p}(x-\right.$ $S)) B-d^{\prime}\left(\mu^{p}(x-S)\right) h$ when $\mu^{s} x=\mu^{p}(x-S)$. Thus, when the bond is set such that $S=h /(1$ $+r$ ), total investment in the risky activity under the property rule is equal to the social optimum. As a result, investment in the risky activity and expected damages are larger than what are socially desirable under a property rule for levels of $S$ below the value $h /(1+r)$, and vice versa.

\section{Strict Liability}

Under a strict-liability rule, the firm pays compensation for damages if damages occur and if the firm is shown to have caused the damage (Harl; Johnson and Ulen; Shavell, 1984a). For example, even though damages occur, scientific knowledge may not be available to determine that the firm's actions caused the damages (Johnson and Ulen), or damaged parties may not be able to prove successfully in court that the firm caused the damages (Cooter). Previous literature on strict liability recognizes that bankruptcy laws or finite firm assets may reduce the incentives for precaution (Cooter; Johnson and Ulen; Rizzo; Shavell 1987, 1984a,b, 1980). In effect, firm decisions do not influence the maximum amount of compensation that the firm can pay. Thus, two cases are considered: one where the firm can compensate fully for damages and one where the firm cannot compensate fully.

In the model analyzed here, the firm's final wealth position is random when decisions are made. As a result, the firm's ability to pay compensation is also random. If $h$ is the level of damage caused by the risky activity when an accident occurs, the potential compensation the firm can pay under strict liability is $\min [h,(1+r)(1$ $-\mu) x$ ] if the risky activity is not successful and $\min [h,(1+r)(1-\mu) x+B]$ if successful.

In effect, three situations may be relevant for the firm and society after the risky activity is conducted. As shown in figure 1, the relevance of the three cases depends on firm size $(x)$, the potential return from the risky activity $(B)$, the riskless rate of return $(1+r)$, and the potential harm $(h)$. In case 1 , where $0 \leq h \leq(1+r)(1$ $-\mu) x$, the firm is always able to compensate fully for harm after conducting the risky activity. In case 2 , where $(1+r)(1-\mu) x \leq h \leq$ $(1+r)(1-\mu) x+B$, the firm is only able to compensate fully for harm if it is successful in 


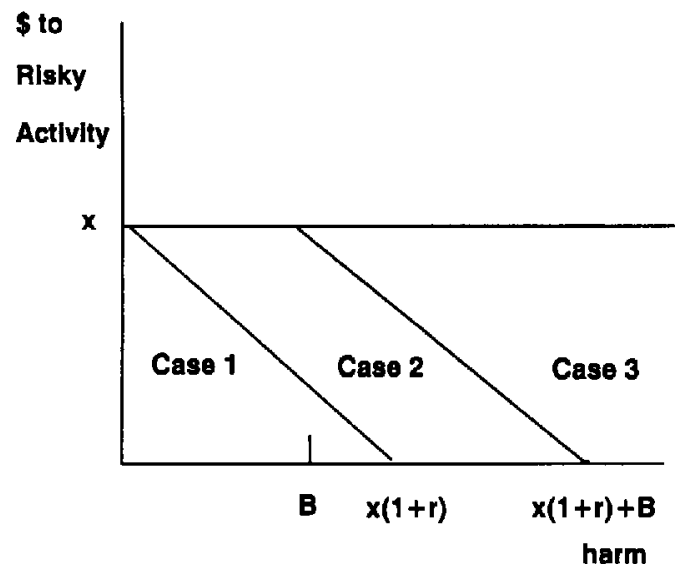

Figure 1. Three cases under liability

the risky activity. ${ }^{10}$ And in case 3 , where $(1+$ $r)(1-\mu) x+B \leq h$, the firm is not able to compensate fully for harm even if it is successful in the risky activity. ${ }^{11}$

In general, to determine the optimal allocation of wealth under a strict-liability rule, the firm must solve

$$
\text { 11) } \begin{aligned}
\max _{0 \leq \mu \leq 1}(1+r)(1-\mu) x+p(\mu x) B \\
-d(\mu x) t\{p(\mu x) \min [h,(1+r)(1-\mu) x+B] \\
+(1-p(\mu x)) \min [h,(1+r)(1-\mu]\}
\end{aligned}
$$

where the first two terms are expected income from the riskless and risky activity, $t$ is the probability that the firm is shown to be responsible for damages, and the last term is expected liability from conducting the risky activity. In general, the firm's decision problem (11) can be analyzed as follows. Given the parameters of the problem, the firm first chooses for each possible case the optimal $\mu_{i}{ }^{2}$, where $i=1,2,3$, for the three cases. From this set of $\mu_{i}$ 's, the firm then chooses the $\mu_{i}{ }^{l}$ that maximizes overall expected profits.

The firm's optimal choice in case 1, where full compensation is possible, is essentially the standard result for a strict liability rule (Shavell 1984a) when bankruptcy or limited liability is not an issue. The firm's first-order condition in case 1 is identical to society's decision rule (4)

\footnotetext{
${ }^{10}$ The line separating case from case 2 in figure 1 is defined by $f(h)=x-h /(1+r)$ for $0 \leq h \leq x(1+r)$.

"The line separating case 2 from case 3 in figure 1 is $g(h)=x$ $-(h-B) /(1+r)$ for $B \leq h \leq x(1+r)+B$.
}

except, because the firm is not sued with certainty, expected liability is now only $t h$. Thus, resources allocated to the risky activity under a liability rule for case 1 are greater than for society's expected net-benefit criteria. ${ }^{12}$ However, investment in the risky activity in case 1 is less than that for the unregulated firm and for the firm under the regulatory standard. A strict liability rule in case 1 is also equivalent to a property rule where the bond is set such that $S=t h /$ $(1+r)$.

The firm's first-order condition for case 2 , where full compensation for damages is only possible if the firm is successful, and the firstorder condition for case 3 , where full compensation is never possible, show how the presence of random firm wealth complicates well-known liability results. In case 2 , expected liability is equal to $t\left\{p\left(\mu_{2} x\right) h+\left(1-p\left(\mu_{2} x\right)\right)(1+r)(1-\right.$ $\left.\left.\mu_{2}\right) x\right\}$, while in case 3 expected liability is equal to $t\left\{p\left(\mu_{3} x\right) B+(1+r)\left(1-\mu_{3}\right) x\right\}$. Because expected liability falls from case 1 to case 2 to case 3 , one would expect that the allocation of wealth to the risky activity should increase in case 2 and case 3 relative to case 1 . In fact, this result is directly observable from figure 1 . For example, case 1 and case 2 are possible when $h \leq B$. For any level of $h \leq B$, the allocation of assets to the risky activity for case 1 must be less than that for case 2 . All three cases are possible when the level of harm is in the range $B$ $\leq h \leq x(1+r)$, which implies that the allocation of assets to the risky activity is lowest for case 1 and greatest for case 3 . When the level of harm is in the range $x(1+r) \leq h \leq x(1+$ $r)+B$, case 2 and case 3 are possible, and the allocation of assets to the risky activity for case 2 must be less than that for case 3 . Only case 3 is possible when $x(1+r)+B \leq h$.

For the multiactivity firm under uncertainty, random firm wealth and the option of bankruptcy can dilute the incentives for safety beyond what is already recognized in the literature. The incentives for safety are also reduced as firm size decreases relative to potential returns. Thus, the results in this section are qualitatively similar to earlier studies (e.g., Shavell 1987), but this dilution grows as potential benefits and/or harm increase relative to firm wealth. A firm that is wealthy relative to $h$ and $B$ will probably choose $\mu_{1}{ }^{4}$ or $\mu_{2}{ }^{2}$, generating a case 1 or case 2 outcome. However, all three cases may

\footnotetext{
12 As Shavell (1984a) notes, a liability rule of the form $h / t$ cre ates the incentive to allocate resources according to the social netbenefit criterion.
} 
be relevant for medium size firms relative to $h$ and $B$. Case 2 or case 3 may be most relevant for the smallest firms relative to $h$ and $B$. Future research is needed to consider the relative importance of three cases for different situationstypes and location of firms in various industries, and how strict liability might provide the incentives to conduct certain risky activities in a small firm setting. ${ }^{13}$

\section{Conclusions}

This analysis shows how four policy approaches create different incentives to conduct risky research activities. All of the approaches are least effective at controlling public risks and providing the incentives to conduct the research activity when the research firm is small in size (defined by wealth) relative to the benefits that may follow from the research. For example, under the fixed-cost regulatory standard, a marginalcost standard, or a property rule, it is very possible that a firm would find a corner solution optimal and allocate no wealth to the risky activity. As a result, public regulation could drive relatively small firms out of the industry, the very firms that are playing a central role in bringing new agricultural biotechnologies to the market.

While this paper begins to address the effects of institutional choice on resource allocation by the firm, many issues remain. Issues for further investigation include risk-averse research firms, dynamics in the research process, learning, and the temporal resolution of uncertainty. Throughout the paper, it is also assumed that a regulatory agency can enforce the different types of policies. However, the costs of implementing and enforcing environmental policies are central to regulation under uncertainty. In the presence of asymmetric and imperfect information, firms may choose which regulatory regime is preferred through compliance with regulatory standards or a property rule or through noncompliance and the liability regime. Thus, further research is needed to analyze how firm decisions depend on the specific design, implementation, and enforcement of the various regulatory mechanisms. Other types of policies warrant

\footnotetext{
${ }^{13}$ As Ringleb and Wiggins find in the context of corporations in hazardous sectors in the United States, legal liability may also create incentives to divest certain hazardous activities of a larger-scale firm into smaller autonomous units to limit exposure to large liability payments.
}

further investigation. For example, joint and several liability is another litigation strategy, which has been applied to toxic waste clean up under the Comprehensive Environmental Response, Compensation, and Liability Act (Tietenberg). Under joint and several liability, one firm can be held responsible for all the damages created by a group of firms. This type of liability could have implications for joint biotechnology research conducted by private firms and public groups such as universities or government agencies.

\section{[Received June 1990; final revision received January 1991.]}

\section{References}

Bromley, D. W., "Property Rules, Liability Rules, and Environmental Economics." J. Econ. Issues 12(1978):4360.

Calabresi, G., and A. D. Melamed. "Property Rules, Liability Rules, and Inalienability: One View of the Cathedral." Harvard Law Rev. 85(1972):1089-1128.

Coase, R. "The Problem of Social Cost." J. Law Econ. 3(1960): 1-44.

Cooter, R. "Liability Rules and Risk Sharing in Environmental and Resource Policy: Discussion." Amer. J. Agr. Econ. 68(1986): $1276-78$.

Crawford, M. "Biotech Companies Lobby for Federal Regulation." Science 248(1990):546-47.

Demsetz, H. "The Exchange and Enforcement of Property Rights." J. Law and Econ. 7(1964):11-26.

Fishelson, G. "Emission Control Policies Under Uncertainty." J. Environ. Econ. and Manage. 3(1976):18997.

General Accounting Office (GAO). "Biotechnology: Managing the Risks of Field Testing Genetically Engineered Organisms." Report to the Chairman, Subcommittee on Oversight and Investigations, Committee on Energy and Commerce, House of Representatives, June 1988.

Harl, N. E. Agricultural Law. New York: Mathew Bender \& Co., 1990.

Johnson, G. V., and T. S. Ulen. "Designing Public Policy Toward Hazardous Wastes: The Role of Administrative Regulations and Legal Liability Rules." Amer. $J$. Agr. Econ. 68(1986):1266-71.

Kahan, M. "Causation and Incentives to Take Care Under the Negligence Rule." J. Legal Stud. 18(1989):42747.

National Institute of Health (NIH). "Guidelines for Research Involving Recombinant DNA Molecules." 51 Federal Register 16958-23393, 7 May 1986.

National Research Council (NRC). Field Testing Genetically Modified Organisms: Framework for Decisions. Washington DC: National Academy Press, 1989.

Office of Agricultural Biotechnology (OAB). Agricultural Biotechnology; Introduction to Field Testing, ed. H. 
Graham and D. R. Mackenzie. Washington DC, March 1990.

"Guidelines for Research with Genetically Modified Organisms Outside Contained Facilities," draft. Washington DC, 21 May 1990.

Office of Science and Technology Policy (OSTP), Executive Office of the President. "Coordinated Framework for Regulation of Biotechnology, Announcement of Policy and Notice for Public Comment," 51 Federal Register 23302-23393, 26 June 1986.

Ringleb, A. H., and S. N. Wiggins. "Liability and LargeScale, Long-Term Hazards." J. Polit. Econ. 98(1990): 574-95.

Rizzo, M. J. "Law Amid Flux: The Economics of Negligence and Strict Liability in Tort." J. Legal Stud. 9(1980):291-318.

Segerson, K. "Risk Sharing in the Design of Environmental Policy." Amer. J. Agr. Econ. 68(1986):1261-65.

Shavell, S. "A Model of the Optimal Use of Liability and Safety Regulation." Rand J. Econ. 15(1984a):271-80.

-_. Economic Analysis of Accident Law. Cambridge MA: Harvard University Press, 1987.
-. "Liability for Harm Versus Regulation of Safety." J. Legal Stud. 13(1984b):357-74.

__. "Strict Liability Versus Negligence." J. Legal Stud. 9(1980):1-25.

Tietenberg, T. H. "Indivisible Toxic Torts: The Economics of Joint and Several Liability." Land Econ. 65(1989):305-19.

Watson, W. D., and R. G. Ridker. "Losses from Effluent Taxes and Quotas Under Uncertainty. J. Environ. Econ. and Manage. 11(1984):310-26.

Weitzman, M. L. "Prices vs. Quantities." Rev. Econ. Stud. 41(1974):477-91.

White; M. J., and D. Wittman. "A Comparison of Taxes, Regulation, and Liability Rules Under Imperfect Information." J. Legal Stud. 12(1983):413-25.

Yohe, G. W. "Substitution and the Control of Pollution: A Comparison of Effluent Charges and Quantity Standards Under Uncertainty. J. Environ. Econ. and Manage. 3(1976):313-24.

"Towards a General Comparison of Price Controls and Quantity Controls Under Uncertainty." Rev. Econ. Stud. 45(1978):229-38. 